\title{
Refining decisions on which primary care patients to screen for glaucoma
}

\author{
BY BRUCE WICK, OD, PhD \& RONALD GALL, OD, MSC
}

${ }^{66} \mathrm{I}$

was the best of times. It was the worst of times." Charles Dickens classic opening to A Tale of Two Cites (1859) might well apply to today's glaucoma patient. On one hand, with today's exquisitely-accurate diagnostic instruments and new management procedures, diagnosis is easier and treatment is better than ever before. On the other hand, up to $50 \%$ of current patients with glaucoma do not know they have the disease ${ }^{1}$ and many practitioners continue to use an intraocular pressure (IOP) and cup-to-disc (C/D) ratio approach to diagnosis. ${ }^{2}$ However, some researchers are working with a systems-approach to help clinicians face the difficult task of deciding what action (risk assessment, follow closely, or consider therapy) to take for patients who may have openangle glaucoma with only subtle signs of damage. ${ }^{3}$

In this paper, we address the issue of refining decisions of which primary care patients to screen for glaucoma. Using currently available instrumentation and clinical research, we provide normative data on specific physical ocular structures resulting in an extension for primary care examination that promises more accurate identification of which primary eye care patients should be screened for glaucoma, bringing more patients with glaucoma closer to "the best of times".

With introduction of the ophthalmoscope (1854), glaucoma came to be defined as an ocular disease characterized by optic nerve damage with associated elevated intraocular pressure., ${ }^{4,5}$ Glaucoma is now considered as a group of ocular diseases, often accompanied by elevated intraocular pressure, that cause progressive optic nerve atrophy and blindness. ${ }^{7}$ In most

\section{ABSTRACT}

INTRODUCTION: Glaucoma, which is often accompanied by elevated intraocular pressure (IOP), causes progressive optic nerve atrophy and blindness. Among ocular structure parameters abnormalities in central corneal thickness (CCT), cup-to-disc (C/D) ratio, inter-eye C/D ratio asymmetry, optic disc area, and neuro-retinal rim area (N-RRA) appear to be highly correlated with glaucoma. We compare these specific ocular structures in a group of young normal pre-presbyopic patients and in a group of patients being treated for glaucoma.

METHODS: After written informed consent, 1433 consecutive normal, and 56 consecutive patients being treated for glaucoma were assessed by including age, race, sex, IOP (NCT), C/D ratio, optic disc area, N-RRA (Optos), central center thickness (CCT), and anterior chamber depth.

RESULTS: Combinations of findings in CCT, C/D ratio, C/D ratio asymmetry, disc area, and N-RRA (assessed by Z-score) were present in $65.52 \%$ of patients being treated for glaucoma and $22.96 \%$ of young normal patients. For young normal patients, overall average CCT was 550.37+/-39.47um.
Overall average C/D ratio was $0.39+/-0.11$. Inter-eye C/D asymmetry was $0.02+/-0.06$. Overall average disc area was $2.46+/-0.49 \mathrm{~mm}^{2}(7863.54+/-$ 1630.42 pixels). Overall average N-RRA was $1.44+/-0.35 \mathrm{~mm}^{2}(4785.88+/-$ 1161.14 pixels). C/D ratio increased modestly with disc area increase, an increase not associated with thinning N-RRA. Thin N-RRA was associated with small optic discs that had large $C / D(t=-8.21, p=0.000, D F=93)$. There was a significant difference between young normal patients and patients being treated for glaucoma in CCT, C/D ratio, C/D ratio asymmetry, disc area, and N-RRA.

CONCLUSION: More than one in five (22.96\%) young normal patients has ocular structure findings similar to those found in patients being treated for glaucoma. These results will help refine decisions on which primary eye care patient to screen for glaucoma.

Key Words : corneal thickness, C/D ratio, optic disc area, neuro-retinal rim area, glaucoma screening 
primary open angle glaucoma cases, high IOP damages the optic nerve causing nerve fiber layer loss that corresponds to a visual field deficit. Other than high IOP, risk factors associated with glaucoma include a large $\mathrm{C} / \mathrm{D}$ ratio, $\mathrm{C} / \mathrm{D}$ asymmetry, small neuro-retinal rim area, large optic disc area, and a thin central corneal thickness.

\section{Intraocular Pressure}

Intraocular pressure is the fluid pressure in the eye measured in millimeters of mercury. The normal range for intraocular pressure (IOP) is $10-20 \mathrm{~mm} \mathrm{Hg}$, with a mean of $15.5 \mathrm{~mm} \mathrm{Hg}{ }^{8}$ This pressure is maintained throughout life and between the sexes, although there is diurnal and possibly also some seasonal variation. ${ }^{9}$ The IOP distribution in the general population is not a normal gaussian distribution, but is skewed toward higher pressures where an associated increase in visual field loss is often present (Figure 1). ${ }^{10}$

In general, the level of intraocular pressure is directly related to the probability of glaucomatous visual field loss. In a population based prevalence survey of more than 5000 individuals aged 40 and over $^{11}$, participants who had a screening intraocular pressure greater than $30 \mathrm{~mm} \mathrm{Hg}$ were over 38 times more likely to have glaucoma (as defined in the study) than individuals with an intraocular pressure below $15 \mathrm{~mm} \mathrm{Hg}$. In the Blue Mountains Eye Study the odds of developing glaucoma were 4 to 7 times higher when the screening intraocular pressure was

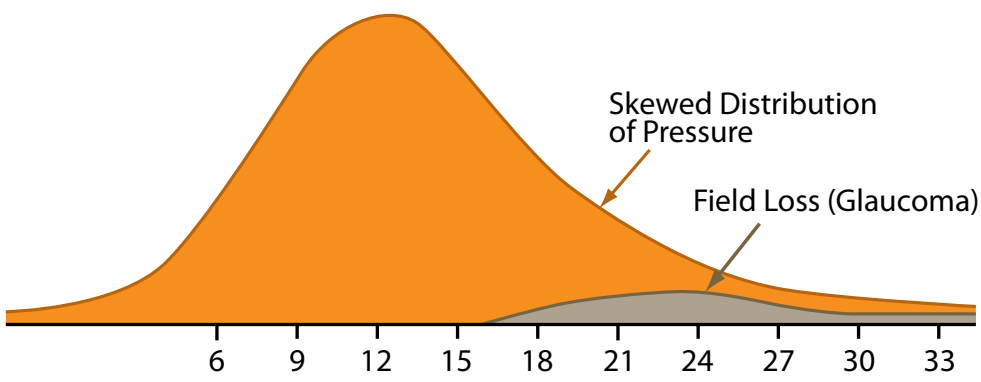

Figure 1 Intraocular Pressure $(\mathrm{mm} \mathrm{Hg})$

No Field Loss

Field Loss

Figure 1: In this diagram of intraocular pressure distribution there is a visible skew toward higher pressures (exaggerated slightly compared to the actual distribution). The average pressure among those with glaucomatous visual field loss is in the low 20s, even though glaucoma is not present in most individuals with similar pressures. And, although it is not common, some individuals with pressures in the upper teens have glaucomatous visual field loss.

greater than $21 \mathrm{~mm} \mathrm{Hg}$ than when there were lower intraocular pressures. ${ }^{12}$ In addition, the chance of developing glaucoma is 2 to 8 times higher in patients with intraocular pressure asymmetry between eyes greater than $3 \mathrm{~mm}$ of $\mathrm{Hg}$ than in patients with smaller or no intraocular pressure asymmetry. ${ }^{13}$

\section{Optic Nerve}

The optic nerve (Cranial Nerve II) is collection of nerve fibers that carry visual information from the retina to the brain. Significantly increased IOP causes progressive optic nerve damage, which manifests as a loss of nerve axons accompanied by a characteristic progressive visual field loss. ${ }^{14}$ The loss of axons gradually becomes visible clinically as an increase in optic nerve cupping. ${ }^{15}$ As a result, one of the most frequent structural observations in patients suspected of having glaucoma is of the optic nerve: historically, assessment of the cup-to-disc $(\mathrm{C} / \mathrm{D})$ ratio is considered to be among the most important observations that can be used to detect glaucoma.

\section{Cup-to-Disc Ratio (C/D)}

$\mathrm{C} / \mathrm{D}$ ratio is the relative comparison of the diameter of the cup to the diaeter of the optic nerve head. A large $\mathrm{C} / \mathrm{D}$ ratio is considered a risk factor for glaucoma. ${ }^{16}$ An early study of cup-to-disc ratios indicated that only $7 \%$ of the normal population had $\mathrm{C} / \mathrm{D}$ ratios of 0.5 or greater and that $86 \%$ of normal $\mathrm{C} / \mathrm{D}$ ratios were less than $0.4 .{ }^{17}$ Because of this study, anyone with a C/D ratio greater than 0.4 was automatically considered a glaucoma suspect. More recent data on 4877 normal individuals suggest 
that, in order to be considered abnormal, $\mathrm{C} / \mathrm{D}$ ratios must be greater than 0.74 horizontally and 0.64 vertically. ${ }^{18}$

\section{Cup-to-Disc (C/D) Ratio Asymmetry}

Cup-to-disc (C/D) ratio asymmetry is the difference in the $C / D$ ratio between the two eyes. Chi et al ${ }^{19}$ found that inter-eye asymmetry of greater than 0.2 for the horizontal optic disc C/D ratio was present less than $10 \%$ of the time. These results have been taken to suggest that, in the presence of approximately symmetrical optic disc area, inter-eye $\mathrm{C} / \mathrm{D}$ ratio asymmetry greater than 0.2 should raise the suspicion of glaucoma.

\section{Other Glaucoma-related Ocular Structures}

Notwithstanding the importance of the $\mathrm{C} / \mathrm{D}$ ratio and inter-eye C/D ratio asymmetry, recent clinical research has identified ocular structures known to change in patients with glaucoma (neuro-retinal rim $\operatorname{area}^{20}$ ) or related to glaucoma (increased optic disc area ${ }^{19}$ and decreased central corneal thickness $[\mathrm{CCT}])^{21}$

\section{Neuro-retinal Rim Area}

(N-RRA)

Neuro-retinal rim area (N-RRA) is the total disc area less the area of the cup $(C / D$ ratio $\times$ Disc area). Of the parameters of the ONH, neuro-retinal rim area (N-RRA) appears to be most highly correlated with glaucomatous damage. ${ }^{20}$ For example, on the Heidelberg Retinal Tomograph (HRT) N-RRA is an important piece of information in addition to the computer-derived cup shape measure. ${ }^{22}$ Previous studies have demonstrated that optic discs with larger over-all areas have larger neuro-retinal rim areas compared to smaller optic discs. ${ }^{23}$ The N-RRA appears to be an important clinical parameter for clinicians to evauate when looking for and monitoring glaucoma, making estimation of the N-RRA an essential part of $\mathrm{ONH}$ examination. ${ }^{24,25}$

\section{Optic Disc Area}

Optic disc area is the surface area of the optic nerve head. The area of the disc varies from 0.92 to $5.54 \mathrm{~mm}^{2}$ in normal patients, with Black patients typically having a significantly larger disc areas than Caucasians. ${ }^{26,27}$ Based on a study of a portion of the Ocular Hypertension Treatment Study (OHTS) participants, it has been suggested that patients with larger optic disc size may have an increased susceptibility to glaucoma. ${ }^{28}$ In a larger disc there is more area for the nerve fibers to fill, allowing for a larger cup (although animal studies have demonstrated that nerves with larger over-all areas tend to have more nerve fibers when compared to nerves with small areas ${ }^{29}$ ). Since the area of the optic disc is large and less of it is occupied by the nerve fiber, the $\mathrm{C} / \mathrm{D}$ ratio could be overestimated. An abnormal $\mathrm{C} / \mathrm{D}$ ratio could occur with a normal optic disc area and a decrease in the number of nerve fibers leaving the eye (as occurs in glaucoma), or with an abnormally large optic disc area and a normal number of nerve fibers.

\section{Central Corneal Thickness (CCT)}

Central corneal thickness (CCT) is thickness in microns of the center of the cornea. The OHTS data document that a thin central cornea is associated with increased risk of glaucoma, irrespective of race. $^{28}$ The cause-and-effect relationship between central corneal thickness (CCT) and glaucoma is not yet clear. However, a patient with a thin cornea can have a falsely low IOP reading.

\section{Research Question}

Parameters of the $\mathrm{CCT}^{28}, \mathrm{C} / \mathrm{D}$ ratio $^{17,18}$, inter-eye $\mathrm{C} / \mathrm{D}$ ratio asymmetry, ${ }^{19}$, optic disc area ${ }^{24,25}$, and $\mathrm{N}^{-R_{R} A^{20}}$ have been investigated and compared for glaucoma patients and age matched normal subjects; C/D ratio ${ }^{14,15}$ and $C / D$ inter-eye asymmetry ${ }^{19}$ have been evaluated for normal subjects. However, although the structures have been individually studied, multiple structure interrelationships have not been investigated in large numbers of normal subjects. Thus, what is not well delineated are the answers to our general research questions:

\section{General Research Questions}

1) Can decisions to determine which patients to screen for glaucoma be refined by determining the normal ranges of specific physical ocular structures?

2) And, can these normative data of specific physical ocular structures be applied to the age range of patients who participated to find those with anatomy similar to glaucoma patients? 
The answers are important because only a small proportion of patients ever develop glaucoma; e.g., it is estimated that between $1.1 \%$ $(11 / 1000$ Caucasian) and $8.8 \%$ (88/1000 Black) of today's young adults will ultimately develop glaucoma $^{30}$, and up to $50 \%$ of current patients with glaucoma do not know they have the disease. ${ }^{1}$

The challenge presented is to investigate in both normal and glaucoma patients, using screening devices available in a routine clinical care setting, and various ocular structural factors (CCT, C/D ratio, inter eye $\mathrm{C} / \mathrm{D}$ ratio asymmetry, optic disc area, and N-RRA) associated with glaucoma. The approach is relating normal and glaucoma specific physical ocular structures to each other; either gold standard testing (e.g., Goldmann tonometry for IOP, Stereo optic nerve photos for C/D evaluation) or screening devices available in routine clinical care (e.g. NCT for IOP, Optos for C/D evaluation), may be used as long as decisions are based on consistent equipment and resulting normative data.

Taken together, answers to our specific research question:

Specific Research Question

- Are there clinically significant numbers of healthy pre-presbyopic patients and patients being treated for glaucoma who have similar specific physical ocular structure relationship?

and our research objective:

Research Objective

- To provide data for young normal patients, gathered using screening devices available in a routine clinical setting, which delineate the normal range of specific physical ocular structures (CCT, C/D ratio, inter eye $\mathrm{C} / \mathrm{D}$ ratio asymmetry, optic disc area, and N-RRA) as well as the interrelation between structure findings -

will allow routine clinical measures to be utilized to refine decisions concerning which primary eye care patients to screen for glaucoma beyond the cup/disc $(C / D)$ ratio and IOP approach .

\section{Methods}

A total of 1433 patients not previously known to have glaucoma were evaluated in two separate clinics located in Houston, Texas (USA) and Oakville, Ontario (Canada). An additional group, selected from the Houston site, included 56 consecutive patients who were being treated for either primary open angle or low pressure glaucoma. After written informed consent was granted, data collected included each patient's age, race (by self-report), sex, date of birth, intraocular pressure (IOPNCT), anterior chamber depth and angle (Pentacam), central corneal thickness (CCT), cup-to-disc ratio (C/D), C/D asymmetry, optic disc area, and neuro-retinal rim area $(\mathrm{N}$ RRA). These data were specifically gathered using routinely available non-invasive clinical care techniques so that the results would be as applicable to other providers as possible (where possible routinely available care procedures were "standardized" to insure their accuracy and use by other providers in the future).

In Houston, consecutive patients were included from the date of study onset. In Oakville, patients were selected based on willingness to have Optos examination. Young normal patients were between ages 4 and 40 years. Patients excluded were aged 4 or less (due to the lack of cooperation) and over age 41 (who were more at risk for glaucoma due to their age). Data from a few patients were not included due to inability to procure accurate anterior segment assessment with Pentacam. Also excluded from the young normal group were patients with glaucoma (progressive visual field defects, visible optic disc damage, and/or progressive nerve fiber layer thinning) and those who had undergone Lasik or corneal transplant surgeries.

\section{C/D, C/D Asymmetry, Disc Area, Neuro-Retinal Rim Area}

\section{Optos}

Images of the retina were captured using the Optos P200 Device, a panoramic 200-degree non-mydriatic screening ophthalmoscope. This retinal image scanner uses red and green laser wavelengths to produce a digital, high resolution color picture which is displayed on a PC monitor. These two laser wavelengths penetrate the retinal structures to different depths, each providing information for interpretation and diagnosis. Panoramic 200-degree images can be viewed, enlarged, annotated, and separated into their color components.

Cup-to-disc ratio was assessed on the red free image using a computer generated tool supplied with the Optos software ( $\mathrm{V}^{2}$ Vantage 2.3.0.70). First, the margins of the cup were traced using the color contours and the bending of blood vessels as a guide. The same technique was used 
to draw the disc margins. This procedure automatically calculated the $\mathrm{C} / \mathrm{D}$ ratio. For each subject, the $\mathrm{C} / \mathrm{D}$ asymmetry was calculated by taking the difference between the right and left eye $\mathrm{C} / \mathrm{D}$ ratio.

Disc area was also determined using the Optos software. The margins of the disc were traced using the color contours as a guide. This procedure automatically calculates the disc area ratio in pixels. Neuroretinal rim area (N-RRA) was calculated by subtracting the area of the cup $(\mathrm{C} / \mathrm{D}$ ratio $\times$ Disc area) from the total disc area.

\section{Conversion from pixels to $\mathrm{mm}^{2}$}

Optical coherence tomography (OCT) is an imaging technique, analogous to ultrasound B scan, that provides cross-sectional images of the retina with micrometer-scale resolution. It provides cross-section morphological features of the optic disc and normal anatomic variations in retinal and retinal nerve fiber layer thickness with 10 micron depth resolution. To estimate disc area in $\mathrm{mm}^{2}$, we collected data for 82 eyes (41 patients), first with Optos to determine disc area in pixels and then for the same patients with OCT to determine disc area in $\mathrm{mm}^{2}$. By comparing Optos values for disc area (in pixels) and OCT values (in $\mathrm{mm}^{2}$ ) for the same patients we developed a conversion factor from pixels to disc area $\left(\mathrm{mm}^{2}\right)$.

\section{Central Corneal Thickness}

In Houston, Pentacam (Occulus Pentacam - Belinea) was performed on every patient to determine central corneal thickness, anterior chamber depth, and the anterior chamber angle in degrees. Pentacam is an instrument that uses a rotating Scheimpflug camera to take multiple images of the anterior segment. The center of the cornea is very precisely measured with this rotational imaging process. Measurements take less than two seconds and minute eye movements are captured and simultaneously corrected. Images are computer analyzed to generate three dimensional images and calculate measurements of the eye. In addition to corneal thickness measurements, the Pentacam provides corneal topography measurement, AC depth, volume, and angle, and pupil diameter assessment. In Oakville, optical pachymetry utilizing OLCR (Optical Low Coherence Reflectometry) technology, with a Haag-Streit Slit lamp-mounted Pachymeter was performed to determine corneal thickness.

\section{Power Calculation}

The goal of statistical power analysis and sample size estimation techniques is to facilitate decisions of how large a sample is needed to enable statistical judgments that are accurate and reliable and how likely statistical tests will be to detect significant differences in a particular situation. ${ }^{31}$ Power indicates the probability that a clinical trial will have a significant (positive) result; that is, have a $\mathrm{p}$-value of less than the chosen significance level (e.g., 0.05). ${ }^{31}$ For a 0.05 level of significance, the corresponding power level is 0.80 . This probability is calculated under the assumption that the difference equals the minimal detectable difference. In clinical trials, the minimum detectable dif- ference is the smallest difference that would be clinically important and biologically plausible.

For example, consider the $\mathrm{C} / \mathrm{D}$ ratio; the minimal detectable difference or "smallest difference" between normal (0.3) and glaucoma (0.5) patients could be 0.2. To calculate the sample size needed for a power level of 0.8 , it may be assumed that for each group (normal and glaucoma) there are equal standard deviations $(+/-0.1)$, degrees of freedom $(\mathrm{df}=100)$ and sample sizes. In this example, the sample size calculation shows that fewer than twenty $(n<20)$ subjects are needed for each group (control and glaucoma) to have the power for a significant difference ( $\mathrm{p}$-value less than 0.05). Thus, our sample size of 1377 young normal eyes and 112 eyes being treated for glaucoma gives us more than ample power to detect clinically significant differences in the parameters studied $(\mathrm{C} / \mathrm{D}, \mathrm{C} / \mathrm{D}$ Asymmetry, Disc Area, Neuro-Retinal Rim Area, and Central Corneal Thickness).

\section{Results}

From our study design we had normative data on 1377 eyes of 702 young normal subjects (621 - normal IOP; 81 - high IOP [>21 $\mathrm{mmHg}]$ ) and 112 eyes of 56 patients being treated for glaucoma. Of the young normal subjects, 291 were male (average age $16.56+/$ 8.39, range 5-40) and 411 were female (average age 19.87+/-9.54, range 4-39). There were 199 Black (181 - normal IOP), 175 Caucasian (168 - normal IOP), 173 Hispanic (153 - normal IOP), 118 Other 
(Asians of Indian and Pakistan origin; 83 - normal IOP), and 37 Asian (Vietnamese and Chinese; 36 - normal IOP) patients. Of the patients being treated for glaucoma, 18 were male (average age $61.40+/-12.42$, range 41-80) and 38 were female (average age $63.92+/-13.29$, range 41-87). There were 20 Black, 10 Caucasian, 14 Hispanic, 9 Other (Asians of Indian and Pakistan origin), and 3 Asian (Vietnamese and Chinese) patients being treated for glaucoma.

\section{Z-Scores}

In statistics, a standard score (also called z-score or normal score) is a dimensionless quantity derived by subtracting the population mean from an individual (raw) score and then dividing the difference by the population standard deviation. Since the Z-Score is dimensionless, individual Z-Scores for CCT, C/D ratio, disc area, $\mathrm{C} / \mathrm{D}$ ratio asymmetry, and N-RRA can be combined through addition into a total ZScore to portray the ocular structure of young normal patients (see Figure 2). For our young normal population the mean total Z-Score was 0.00 (range -7.32 to +9.24 ), with an increasing plus number indicating increasing prevalence of ocular structures that have been associated with glaucoma (CCT, C/D ratio, disc area, C/D ratio asymmetry, and N-RRA). Again, for our young normal population, the standard deviation was $2.30 ; 77.04 \%$ of young normal patients had a Z-score less than $2.30,22.96 \%$ of patients were more than $1 \mathrm{SD}$ greater than the mean, and $6.48 \%$ were more than 2SD greater than the mean. For the

\section{Glaucoma-Related Ocular Structure (Z-Score)}

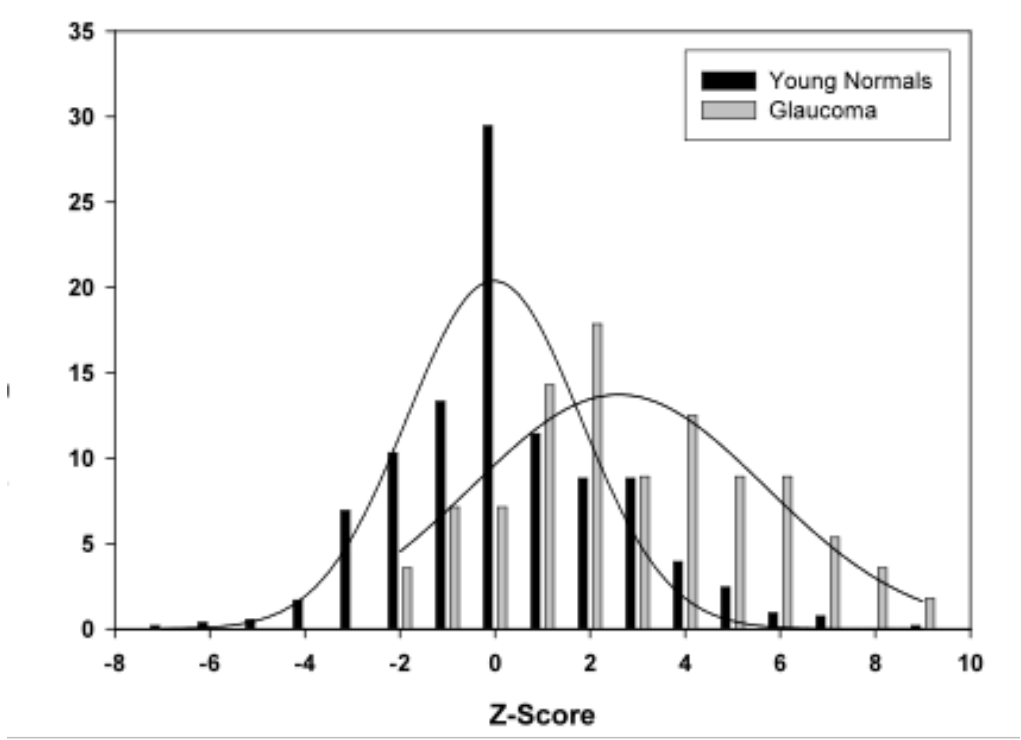

Figure 2: For our young normal population the mean Z-Score was 0.00 (range -7.32 to +9.24), with an increasing plus number indicating an increasingly glaucoma-related structure. The standard deviation was 2.30; 77.04\% of young normal patients had a $Z$-score less than 2.30. For the glaucoma patients, using a Z-Score derived from the ocular structure mean and standard deviation of young normals, the mean Z-Score was 3.25 (range -2.09 to +11.30). A Z-Score greater than 2.3 was present in $65.52 \%$ of glaucoma patients and $22.96 \%$ of young normal patients.

patients being treated for glaucoma, using individual structure Z-Scores derived from the ocular structure mean and standard deviation of young normal patients, the mean total Z-Score was 3.25 (range -2.09 to +11.30$)$. A Z-Score $>2.30$ was present in $65.52 \%$ of patients being treated for glaucoma.

These results demonstrate a positive answer to our:

Specific Research Question: are there clinically significant numbers of healthy pre-presbyopic patients and patients being treated for glaucoma who have similar specific physical ocular structure relationship?

$Z$-scores $>2.30$ are present in $22.96 \%$ of young normal patients and $65.52 \%$ of patients being treated for glaucoma.

Notwithstanding the fact that $22.96 \%$ (more than one in five) of young patients had Z-scores within the range of those present in patients being treated for glaucoma, there are statistically significant differences between young normal patients and patients being treated for glaucoma. Using a two sample t-test 
(two-tailed, independent samples, unequal variance) for between-group differences, $t$-values were calculated, associated $\mathrm{p}$-values estimated from a table $\mathrm{e}^{32}$, and degrees of freedom (df) assumed two less than the total number analyzed. The between-group difference of the young normal and patients being treated for glaucoma groups and its significance are shown in Table 1.

At the 0.05 level or higher:

- C/D ratio asymmetry of the patients being treated for glaucoma $(0.08+/-0.12)$ was greater than the normal group $(0.02+/-$ $0.06)$.

At the 0.02 level or higher:

- Corneal thickness of the patients being treated for glaucoma (535.64+/-43.28) was thinner than the normal group $(550.37+/-39.47) .{ }^{\text {b }}$

At the 0.01 level or higher:

- Disc area of the patients being treated for glaucoma $(8626.01+/-2051.50)$ was larger than the normal group (7863.54+/-1630.42).
At the 0.001 level or higher:

- Age of the patients being treated for glaucoma $(62.91+/$ 13.05) was higher than the normal group (19.09+/-9.40).

- C/D ratio of the patients being treated for glaucoma $(0.57+/$ $0.09)$ was larger than the normal group (0.39+/-0.11).

n Neural-retina rim area (N-RRA) of the patients being treated for glaucoma (3593.30+/-922.30) was smaller than the normal group (4785.88+/-1161.14)

Data below elucidate our research objective.

Research Objective:

- To provide data for young normal patients, gathered using screening devices available in a routine clinical setting, which delineate the normal range of specific physical ocular structures (CCT, C/D ratio, inter eye $\mathrm{C} / \mathrm{D}$ ratio asymmetry, optic disc area, and N-RRA) as well as the interrelation between structure findings.
Results for specific ocular structures of the 1377 eyes of young normal patients were as follows:

- central corneal thickness of $550.37+/-39.47 \mathrm{~mm}$.

- C/D ratio of $0.39+/-0.11$

- between eye $\mathrm{C} / \mathrm{D}$ ratio difference of $0.02+/-0.06$

n disc area of $7863.54+/-1630.42$ pixels

n-RRA of $4785.88+/-1161.14$ pixels

Data for each area assessed are presented in Table 2.

There were several parameters that were different in comparison of the various groups in the young normal cohort at a range of significance levels (see Table 2):

At the 0.01 level or higher:

- Female patients had thinner central corneal thickness $(546.92+/-38.26 \mathrm{~mm})$ than male patients $^{\mathrm{b}}(555.01+/-40.55 \mathrm{~mm})$.

- Caucasian patients had smaller disc areas (7392.73+/-1714.24) than the over-all study average (7863.54 +/-1630.42).

\section{TABLE 1}

\section{GROUP COMPARISON}

\begin{tabular}{|c|c|c|c|c|c|c|}
\hline & \multicolumn{2}{|c|}{ Young Adult } & \multicolumn{2}{|c|}{ Glaucoma } & \multicolumn{2}{|c|}{ Group Comparison } \\
\hline$N=$ & Total & 702 & Total & 56 & & \\
\hline & Male & 291 & Male & 18 & & \\
\hline & Female & 411 & Female & 38 & & \\
\hline Eyes $\mathrm{N}=$ & & 1377 & & 112 & & \\
\hline & Mean & SD & Mean & SD & T-value & $\mathrm{p}$-value \\
\hline Age & 19.09 & 9.40 & 62.91 & 13.05 & 24.55 & $<0.001$ \\
\hline CCT & 550.37 & 39.47 & 535.64 & 43.28 & 2.45 & $<0.02$ \\
\hline$C / D$ & 0.39 & 0.11 & 0.57 & 0.09 & 13.58 & $<0.001$ \\
\hline C/D Asymmetry & 0.02 & 0.06 & 0.08 & 0.12 & 2.17 & $<0.05$ \\
\hline Disc Area & 7863.54 & 1630.42 & 8626.01 & 2051.50 & 2.71 & $<0.01$ \\
\hline N-RRA & 4785.88 & 1161.14 & 3593.30 & 922.30 & 9.10 & $<0.001$ \\
\hline
\end{tabular}


TABLE 2a

YOUNG ADULT DATA

\begin{tabular}{|c|c|c|c|c|c|c|c|c|c|c|c|c|c|c|}
\hline \multicolumn{3}{|l|}{$\begin{array}{l}\text { Young Normal } \\
(\mathrm{IOP} \leq 21)\end{array}$} & \multicolumn{2}{|c|}{$\begin{array}{l}\text { High IOP* } \\
(\mathrm{IOP}>21)\end{array}$} & \multicolumn{2}{|l|}{$\begin{array}{l}\text { Asian } \\
(\mathrm{IOP} \leq 21)\end{array}$} & \multicolumn{2}{|l|}{$\begin{array}{l}\text { Black } \\
(\mathrm{IOP} \leq 21)\end{array}$} & \multicolumn{2}{|l|}{$\begin{array}{l}\text { Hispanic } \\
(\mathrm{IOP} \leq 21)\end{array}$} & \multicolumn{2}{|c|}{$\begin{array}{l}\text { Other (Pakistani \& } \\
\text { Indian Descent) } \\
\text { (IOP } \leq 21)\end{array}$} & \multicolumn{2}{|c|}{$\begin{array}{l}\text { Caucasian } \\
(\mathrm{IOP} \leq 21)\end{array}$} \\
\hline $\mathrm{N}=$ & Total & 621 & Total & 81 & Total & 36 & Total & 181 & Total & 153 & Total & 83 & Total & 168 \\
\hline & Male & 260 & Male & 31 & Male & 19 & Male & 63 & Male & 72 & Male & 34 & Male & 72 \\
\hline & Female & 361 & Female & 50 & Female & 17 & Female & 118 & Female & 81 & Female & 49 & Female & 96 \\
\hline Eyes $\mathrm{N}=$ & & 1377 & & 134 & & 72 & & 362 & & 306 & & 166 & & 336 \\
\hline & Mean & SD & Mean & SD & Mean & SD & Mean & SD & Mean & SD & Mean & SD & Mean & SD \\
\hline Age & 19.09 & 9.40 & 13.63 & 5.52 & 21.28 & 9.96 & 19.03 & 9.56 & 17.59 & 8.90 & 16.82 & 8.33 & 21.18 & 9.62 \\
\hline IOP & 15.68 & 2.92 & 22.48 & 3.13 & 15.09 & 2.61 & 15.66 & 2.93 & 16.23 & 2.81 & 15.99 & 2.99 & 15.13 & 2.98 \\
\hline CCT & 550.37 & 39.47 & 583.75 & 42.49 & 550.64 & 34.59 & 533.36 & 37.81 & 560.61 & 39.85 & 553.25 & 37.45 & 553.51 & 39.20 \\
\hline C/D & 0.39 & 0.11 & 0.41 & 0.11 & 0.43 & 0.11 & 0.41 & 0.11 & 0.39 & 0.11 & 0.40 & 0.12 & 0.34 & 0.10 \\
\hline C/D Asymmetry & 0.02 & 0.06 & 0.02 & 0.05 & 0.0 & 0.05 & 0.02 & 0.06 & 0.02 & 0.06 & 0.02 & 0.07 & 0.01 & 0.04 \\
\hline AC Angle & 37.45 & 11.99 & 37.49 & 9.98 & 34.71 & 6.26 & 37.95 & 7.36 & 38.32 & 17.66 & 35.83 & 6.50 & 37.11 & 6.91 \\
\hline AC/Depth & 3.31 & 0.32 & 3.30 & 0.34 & 3.29 & 0.36 & 3.32 & 0.32 & 3.30 & 0.31 & 3.26 & 0.33 & 3.37 & 0.30 \\
\hline Disc Area & 7863.54 & 1630.42 & 7579.55 & 1451.55 & 8319.47 & 1897.47 & 8003.52 & 1616.69 & 7976.01 & 1410.13 & 8099.01 & 1480.79 & 7392.73 & 1714.24 \\
\hline N-RRA & 4785.88 & 1161.14 & 4338.79 & 845.64 & 4681.97 & 1143.41 & 4704.78 & 1044.42 & 4863.46 & 1057.86 & 4799.89 & 1106.60 & 4841.50 & 1379.51 \\
\hline N-RRA Asymmetry & 119.50 & 677.05 & 107.41 & 599.85 & 61.29 & 486.74 & 124.82 & 626.66 & 118.14 & 759.08 & 45.62 & 703.58 & 208.68 & 644.06 \\
\hline
\end{tabular}

*Included in the high IOP group are: 1 Asian, 18 Black, 20 Hispanic, 35 Other, and 7 Caucasian who are not included in the respective Ethnicity columns

\section{TABLE 2B}

\section{T-TEST COMPARISON}

\begin{tabular}{|c|c|c|c|c|c|c|c|}
\hline Race & IOP & CCT & $C / D$ & Angle & AC Depth & Disk Area & N-RRA \\
\hline $\mathrm{CxO}$ & 0.02 & & 0.001 & & 0.05 & 0.001 & \\
\hline $\mathrm{CxH}$ & 0.001 & & 0.001 & & & 0.01 & \\
\hline$C \times B$ & & 0.001 & 0.001 & & & 0.01 & 0.001 \\
\hline CXA & & & 0.001 & 0.05 & & 0.01 & 0.001 \\
\hline CxOverAll & & & 0.001 & & & 0.01 & \\
\hline \multicolumn{8}{|l|}{$\mathrm{OxH}$} \\
\hline $\mathrm{OxB}$ & & 0.001 & & 0.02 & & & \\
\hline OxA & & & & & & & 0.02 \\
\hline $\mathrm{H} \times \mathrm{B}$ & & 0.001 & & & & & 0.02 \\
\hline $\mathrm{H} \times \mathrm{A}$ & 0.02 & & 0.05 & 0.05 & & & 0.001 \\
\hline BXA & & 0.05 & & 0.01 & & & \\
\hline
\end{tabular}

*Caucasian smaller C/D; Caucasian smaller disk area; Black thinner cornea; Asian and black smaller N-RRA

\section{HIGH IOP VS NORMAL IOP}

\begin{tabular}{|l|l|l|l|l|l|}
\hline IOP & CCT & C/D & Angle & AC Depth & Disk Area \\
\hline & 0.01 & 0.01 & & & 0.05 \\
\hline & Thicker & larger & & 0.001 \\
\hline
\end{tabular}

*High IOP thicker cornea, larger C/D, smaller disk area, smaller N-RRA 
At the 0.001 level or higher:

- Caucasian patients had smaller $\mathrm{C} / \mathrm{D}$ ratios $(0.34+/-0.1)$ than the over-all study average $(0.39+/-0.11)$.

- Black patients had thinner central corneal thickness $(533.36+/-37.81 \mathrm{~mm})$ than other groups (except Asians $\mathrm{p}=0.05)$.

- Asian (4681.97+/-1143.41) and Black (4704.78+/-1044.42) patients had smaller N-RRA than the N-RRA of Caucasian patients $(4841.50+/-1379.51$ pixels).

There were data on 134 eyes of 81 young normal patients with ocular hypertension (IOP $>21$, range 22-36). Their average age was $13.63+/-5.52$, range 6-38. Compared to the over-all group, these patients also had differences at a range of significance levels:

At the 0.05 level or higher:

- Smaller disc area 7579.55+/1451.55 pixels

At the 0.01 level or higher:

- Thicker cornea $583.75+/$ $42.29 \mathrm{~mm}$

- Larger C/D ratio $0.41+/-0.11$ At the 0.001 level or higher:

- Smaller N-RRA 4338.79+/845.64 pixels

For young-normal patients with thin N-RRA various relations were investigated:

- There was no relation to age $(t=-0.04, p=0.966, d f=98)$ - i.e., older patients were not more likely to have a thinner N-RRA.

- There was no relation to IOP $(t=-1.00, p=0.320, d f=91)-$ i.e., patients with higher IOP were not more likely to have a thinner N-RRA.
There was no relation to corneal thickness $(\mathrm{t}=1.53 \mathrm{p}=0.13$, $\mathrm{df}=98)$. i.e., patients with thinner corneas were not more likely to have a thinner N-RRA.

- Increase in disc area was accompanied by an increase in $\mathrm{C} / \mathrm{D}$ (Figure 3) - this increase was associated with a non-significant increase in N-RRA ( $t=0.99$ $\mathrm{p}=0.32, \mathrm{df}=98)$.

- Small discs which had a C/D greater than 0.5 tended to have small N-RRA $(\mathrm{t}=-8.21 \mathrm{p}=0.000$, $\mathrm{df}=93$ ).

\section{The Relation Between}

\section{Structures}

Pearson's Chi-square (ChiSq) is used to test whether data samples are different enough in some characteristic that we can generalize that the populations from which our samples are drawn are also different in the characteristic. Presuming that our young normal patient group's ONH structure can be extrapolated to represent the population from which it was sampled, we accepted a chi-square probability of .05 or less as justification for asserting that our young normal patients had ocular structure relations different from those expected by chance.

There were complete data on 532 young normal patients. We present Chi-square analysis for the right eye for differences from expected findings for the various parameters and their interactions (see Table 3). The $\mathrm{C} / \mathrm{D}$ ratio and N-RRA were both different from expected findings at greater than the $\mathrm{p}(\mathrm{ChiSq})=0.05$ level and the over-all data for a single parameter were different

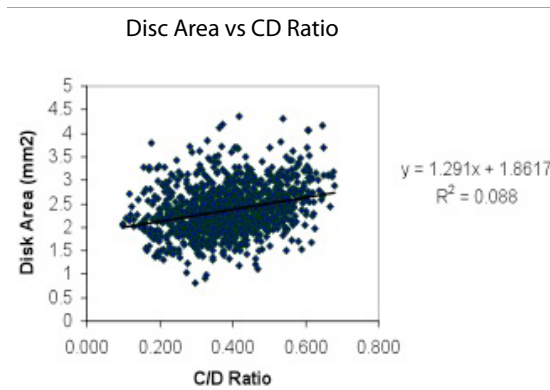

Figure 3: Data presented are for 1404 eyes (702 patients - 621 with normal and 81 with high IOP $[>21 \mathrm{mmHg}]$ ). Increase in disc area was accompanied by a modest increase in $C / D$ and $N-R R A$. Small nerves which had a large $C / D$ tended to have small N-RR $A$ (t $t=-8.21$ $p=0.000, d f=93)$.

from expected at $\mathrm{p}(\mathrm{ChiS} \mathrm{q})=0.000$ $(\mathrm{ChiSq}=26.419)$. For interaction of two parameters the $\mathrm{C} / \mathrm{D}+\mathrm{C} / \mathrm{D}$ asymmetry, C/D + N-RRA, C/D asymmetry $+\mathrm{N}-\mathrm{RRA}$ and Disc Area + N-RRA were all different from expected findings at greater than $p($ ChiSq $)=0.028$ and the overall data for a two parameter interac tion were different from expected at $\mathrm{p}(\mathrm{ChiSq})=0.000(\mathrm{ChiSq}=83.877)$. For interaction of three parameters, ChiSq is not strictly appropriate and correction needs to be made due to the small numbers of expected findings. When analyzed with cor rection for continuity, the total ChiSq is very high $(p(C h i S q)=0.000, \quad$ ChiSq $=81.540)$. With correction for continuity, the multiple interactions of $\mathrm{CCT}+$ $\mathrm{C} / \mathrm{D}+$ Disc Area, CCT + C/D + N-RRA, CCT + C/D asymmetry + Disc Area, and C/D + C/D asymmetry + N-RRA were all different from expected findings at greater than $\mathrm{p}(\mathrm{ChiSq})=0.016$. 
TABLE 3A

SINGLE PARAMETER - 1SD

\begin{tabular}{|l|c|c|c|c|}
\hline & \multicolumn{2}{|c|}{ Suspicious } & \multicolumn{2}{c|}{ Not-suspicious } \\
\hline & Observed & Expected & Observed & Expected \\
\hline CCT & 93 & 84.40 & 439 & 447.60 \\
\hline C/D & 120 & 84.40 & 412 & 447.60 \\
\hline C/D Asymmetry & 81 & 84.40 & 451 & 447.60 \\
\hline Disc Area & 98 & 84.40 & 434 & 447.60 \\
\hline N-RRA & 66 & 84.40 & 466 & 447.60 \\
\hline & & & 0.000 & \\
\hline
\end{tabular}

SINGLE PARAMETER - 2SD

\begin{tabular}{|c|c|c|c|c|c|}
\hline & \multicolumn{2}{|c|}{ Suspicious } & \multicolumn{2}{|c|}{ Not-suspicious } & \multirow[b]{2}{*}{ ChiSq } \\
\hline & Observed & Expected & Observed & Expected & \\
\hline CCT & 10 & 12.10 & 522 & 519.90 & \\
\hline$C / D$ & 16 & 12.10 & 516 & 519.90 & \\
\hline C/D Asymmetry & 20 & 12.10 & 512 & 519.90 & 0.023 \\
\hline Disc Area & 19 & 12.10 & 513 & 519.90 & \\
\hline N-RRA & 3 & 12.10 & 529 & 519.90 & 0.009 \\
\hline & & & & Total X2 & 0.001 \\
\hline
\end{tabular}

TABLE 3B

TWO INTERACTIONS

\begin{tabular}{|c|c|c|c|c|c|}
\hline & \multicolumn{2}{|c|}{ Suspicious } & \multicolumn{2}{|c|}{ Not-suspicious } & \multirow[b]{2}{*}{ ChiSa } \\
\hline & Observed & Expected & Observed & Expected & \\
\hline$C C T+C / D$ & 20 & 20.977 & 512 & 511.023 & \\
\hline$C C T+C / D$ Asymmetry & 9 & 14.160 & 523 & 517.840 & \\
\hline CCT + Disc Area & 16 & 17.132 & 516 & 514.868 & \\
\hline$C C T+N-R R A$ & 11 & 11.538 & 521 & 520.462 & \\
\hline$C / D+C / D$ Asymmetry & 28 & 18.271 & 504 & 513.729 & 0.023 \\
\hline C/D + Disc Area & 26 & 22.105 & 506 & 509.895 & \\
\hline$C / D+N-R R A$ & 45 & 14.887 & 487 & 517.113 & 0.000 \\
\hline C/D Asymmetry + Disc Area & 21 & 14.921 & 511 & 517.079 & \\
\hline C/D Asymmetry + N-RRA & 17 & 10.049 & 515 & 521.951 & 0.028 \\
\hline \multirow[t]{2}{*}{ Disc Area + N-RRA } & 4 & 12.158 & 528 & 519.842 & 0.019 \\
\hline & & & & Total X2 & 0.000 \\
\hline
\end{tabular}

\section{TABLE 3C}

\section{THREE INTERACTIONS}

\begin{tabular}{|c|c|c|c|c|c|}
\hline & \multicolumn{2}{|c|}{ Suspicious } & \multicolumn{2}{|c|}{ Not-suspicious } & \multirow[b]{2}{*}{ ChiSq } \\
\hline & Observed & Expected & Observed & Expected & \\
\hline$C C T+C / D+C / D$ Asymmetry & 4 & 3.194 & 528 & 528.806 & \\
\hline$C C T+C / D+$ Disc Area & 11 & 3.864 & 521 & 528.136 & 0.001 \\
\hline$C C T+C / D+N-R R A$ & 9 & 2.602 & 523 & 529.398 & 0.000 \\
\hline $\mathrm{CCT}+\mathrm{C} / \mathrm{D}$ Asymmetry +Disc Area & 7 & 2.608 & 525 & 529.392 & 0.013 \\
\hline CCT + C/D Asymmetry + N-RRA & 2 & 1.757 & 530 & 530.243 & \\
\hline CCT + Disc Area + N-RRA & 1 & 2.125 & 531 & 529.875 & \\
\hline C/D + C/D Asymmetry + Disc Area & 7 & 3.366 & 525 & 528.634 & \\
\hline$C / D+C / D$ Asymmetry + N-RRA & 13 & 2.267 & 519 & 529.733 & 0.000 \\
\hline $\mathrm{C} / \mathrm{D}+$ Disc Area + N-RRA & 3 & 2.742 & 529 & 529.258 & \\
\hline \multirow[t]{2}{*}{ C/D Asymmetry + Disc Area + N-RRA } & 2 & 1.851 & 530 & 530.149 & \\
\hline & & & & Total $X^{2}$ & 0.000 \\
\hline
\end{tabular}

\section{TABLE 3D}

\section{FOUR OR MORE INTERACTIONS}

\begin{tabular}{|l|c|c|c|}
\hline & \multicolumn{2}{|c|}{ Suspicious } & Not-suspicious \\
\hline CCT + C/D + C/D Asymmetry + Disc Area & Observed & Expected & Observed \\
\hline$C C T+C / D+C / D$ Asymmetry + N-RRA & 2 & 0.588 & 530 \\
\hline$C / D+C / D$ Asymmetry + Disc Area + N-RRA & 2 & 0.396 & 530 \\
\hline & 2 & 0.418 & 531.412 \\
\hline$C C T+C / D+C / D$ Asymmetry + Disc Area + N-RRA & 1 & 531.604 & \\
\hline
\end{tabular}




\section{Between site measures}

Between site measures were generally not significantly different. There were smaller over-all Disc Area in Canada (7087.28+/1871.16 vs $7392.73+/-1714.24$ pixels) and smaller over-all N-RRA in Canada (4413.98+/-1263.43 vs $4851.50+/-1379.51$ pixels). These differences were significant at the 0.01 level when comparing Caucasian patients from Canada and the US.

\section{Optos Measures}

Conversion from pixels to disc area in $\mathrm{mm}^{2}$

We developed a conversion from Optos measures in pixels to disc area in $\mathrm{mm}^{2}$. The result is shown in Figure 4. This conversion, which was determined by comparison of Optos and OCT performed on 82 eyes, is pixels multiplied by 0.0003 .

\section{Reliability}

We investigated reliability of Optos measurements in three ways. First, we measured disc area with two scorings of one Optos measure by the same examiner on separate occasions on 20 patients. There was no significant difference, testretest reliability (coefficient of cor relation) was 0.91 , and Reliability (Standard Error of Measurement) at the $95 \%$ confidence interval (CI) was 415 pixels $\left(0.12 \mathrm{~mm}^{2}\right)$. Sec ond, we measured $\mathrm{C} / \mathrm{D}$ ratio with two scorings of one Optos mea sure by the same examiner on sep arate occasions on 20 patients and found no significant difference, a correlation of 0.79 , and a $95 \% \mathrm{CI}$ of 0.034 . Third, we measured disc area with two different Optos im-

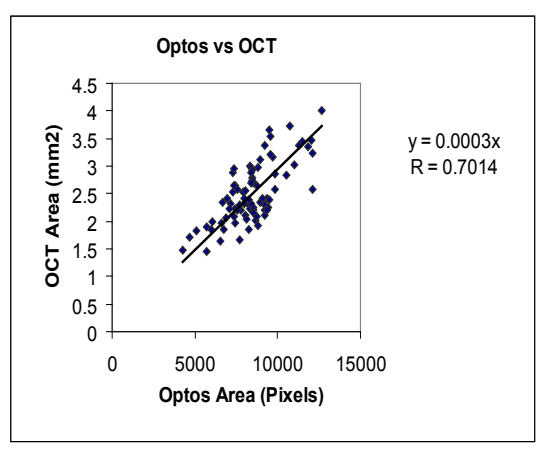

Figure 4: Data are for 82 eyes (41 patients). Measurements were made first with Optos to determine disc area in pixels and then for the same patients with OCT to determine disc area in $\mathrm{mm}^{2}$. The figure compares Optos values for disc area (in pixels) and OCT values (in $\mathrm{mm}^{2}$ ) for the same patients. The conversion factor from pixels to disc area $\left(\mathrm{mm}^{2}\right)$ is pixels times 0.003. The data are modestly correlated $(r=0.70)$; we attribute the lack of higher correlation to "noise" between the two sets of data collected.

ages on separate occasions for 20 eyes and found a significant difference $(\mathrm{t}=-3.19, \mathrm{p}=0.01)$, a cor relation of 0.39 , and a $95 \% \mathrm{CI}$ of 171 pixels $\left(0.05 \mathrm{~mm}^{2}\right)$. Based on our average of 7863.54 pixels/op tic nerve, 171 pixels is about $2.2 \%$ (or in area, the average optic nerve would be $2.36 \mathrm{~mm}^{2}$ with a confi dence of $0.05 \mathrm{~mm}^{2}$ ).

\section{Power Calculation}

Using data from this study (sample size, C/D ratios and standard deviations for each group) the power level approaches 1 which indicates that these results have a greater level of power than 0.8 and level of statistical significance greater than 0.05 .

\section{Discussion}

The clinical dilemma is that only a small proportion of patients ever develop glaucoma, and up to $50 \%$ of current patients with glaucoma do not know they have the disease. From our Research Objective:

-To provide data for young normal patients, gathered using screening devices available in a routine clinical setting, which delineate the normal range of specific physical ocular structures (CCT, C/D ratio, inter eye $\mathrm{C} / \mathrm{D}$ ratio asymmetry, optic disc area, and N-RRA) as well as the interrelation between structure findings.

For young normal patients a statistically abnormal structure related to glaucoma (1SD from the mean) was a:

- central corneal thickness of $510.90 \mu \mathrm{m}(550.37+/-39.47)$ or less,

口 C/D ratio of $0.50(0.39+/-$

0.11 ) or more,

n Disc area of 9493.96 pixels (7863.54 +/- 1630.42); $2.85 \mathrm{~mm}^{2}$ or more,

- Between eye $\mathrm{C} / \mathrm{D}$ ratio asymmetry of $0.08(0.02+/-0.06)$ or more, and

- Neuro-retinal rim area of 3624.74 pixels $(4785.88+/$ 1161.14); $1.09 \mathrm{~mm}^{2}$ or less.

The mean total Z-Score for our young normal population was 0.00 $+/$ - 2.30 (range -7.32 to +9.24 ); $77.04 \%$ of young normal patients had a Z-score $<2.30,22.96 \%$ of patients were more than $1 \mathrm{SD}$ greater than the mean (Z-score $>2.30$ ), and $6.48 \%$ were more than 2SD greater than the mean. For the patients being treated for 
glaucoma, using individual structure Z-Scores derived from the ocular structure mean and standard deviation of young normal patients, the mean total Z-Score was 3.25 (range -2.09 to +11.30$)$. A Z-Score $>2.30$ was present in $65.52 \%$ of patients being treated for glaucoma.

There are similarities in specific physical ocular structures between a clinically significant number $(22.96 \%)$ of healthy pre-presbyopic patients and patients being treated for glaucoma. These results provide an affirmative answer to our Specific Research Question:

- Are there clinically significant numbers of healthy pre-presbyopic patients and patients being treated for glaucoma who have similar specific physical ocular structure relationship?

In addition to the association (overlap) in IOP ranges between normal patients and those with glaucomatous visual field loss (see Figure 1), we found that there is also a significant overlap in the normal ranges of CCT, C/D ratio, C/D ratio asymmetry, disc area, and N-RRA between young normal patients and patients being treated for glaucoma (see Figure 2). Taken together, and using clinical, along with family risk factors, IOP values, and screening visual field (e.g., frequency doubling), these results can be used to refine decisions on which primary care patient to screen for glaucoma.

The physical ocular structures (CCT, C/D ratio, C/D ratio asymmetry, optic disc area and N-RRA) of subjects with abnormal findings (greater than one standard deviation from the mean) are related in Table
3. The $\mathrm{C} / \mathrm{D}$ ratio and $\mathrm{N}-\mathrm{RRA}$ were different than expected by chance as were interactions between $\mathrm{C} / \mathrm{D}$ $+\mathrm{C} / \mathrm{D}$ asymmetry, C/D + N-RRA, $\mathrm{C} / \mathrm{D}$ asymmetry $+\mathrm{N}-\mathrm{RRA}$, and Disc Area + N-RRA. Further, the relation between multiple physical ocular structures CCT $+\mathrm{C} / \mathrm{D}+$ Disc Area, CCT + C/D + N-RRA, $\mathrm{CCT}+\mathrm{C} / \mathrm{D}$ asymmetry + Disc Area, and $\mathrm{C} / \mathrm{D}+\mathrm{C} / \mathrm{D}$ asymmetry $+\mathrm{N}-\mathrm{RRA}$ were also different than expected by chance (see Table 3). The frequent appearance of CCT in the statistically significant multiple interactions of our young adults compares well with the OHTS data where a relation between thin CCT and glaucoma was found. ${ }^{28}$

\section{Study Limitations}

Study limitations include the testing approach, examination technique, lack of definition of race, and the patients on whom it was done. Recall that our testing approach is to determine the normal values (range, mean, and standard deviation) of glaucoma specific physical ocular structures and relating these for young normal and glaucoma patients. Either screening devices available in routine clinical care (e.g. NCT for IOP, Optos for C/D evaluation) or gold standard testing (e.g., Goldmann tonometry for IOP, Stereo optic nerve photos for C/D evaluation) may be used. Once the normative data have been determined it is irrelevant which clinical equipment was used; it is only required that decisions as to which structures are abnormal be made by applying equipment consistently between groups.
Our design is limited by the examination technique. We relied on ophthalmic examination and young age to maximize the probability that the young subjects did not manifest glaucomatous neuropathy. We performed threshold visual fields and nerve fiber analysis (GDx) on most young patients with abnormal ocular structure and none of them were identified with visual field or nerve fiber layer defects (and the vast majority also had normal IOP measures). As a result, we think it is unlikely that the normative ocular structure findings in our young patients were significantly influenced by the presence of patients with glaucoma.

Results comparing different ethnic groups depend on the definition of race used in the study. We used selfreported race in analysis (as have many other studies) and self-report of race is frequently unreliable. For example, in the Bureau of Census' Current Population Survey (March 1971 and March 1972) 34.2\% of the same household reported different ethnic identities. ${ }^{33}$ Because self-report is not always reliable it is possible that some persons were misclassified. Misclassification would weaken our ability to identify differences among ethnic groups. Further, our study was limited to persons living at just two separate sites (Houston, Texas and Oakville, Ontario) and may not generalize to persons of similar reported ethnicity living elsewhere.

Our study included young patients coming for an eye examination and was not population based. It is possible that persons who feel they require a vision examination, who 
often have a significant refractive error, have different parameters of CCT, $\mathrm{C} / \mathrm{D}$ ratio, inter eye $\mathrm{C} / \mathrm{D}$ ratio asymmetry, optic disc area, and N-RRA than those who do not seek eye examinations. The aver age refractive error of the patients was $-1.68-2.46$ (range +7.25 to $-11.50 \mathrm{DS} ; 0.00$ to $-5.25 \mathrm{DC})$. Only $0.91 \%$ were highly myopic $(>-8.00)$ patients (who have been shown to be at greater risk for glaucoma and who tend to have large optic disc areas). ${ }^{23}$ This, plus our finding that the average optic disc area was well within expected limits (see below), makes it likely that our results will generalize reasonably well to the persons with little or no refractive error who make up a large portion of the population.

\section{Disc and N-RRA Area}

Although digitized fundus photographs, confocal scanning laser ophthalmoscopy, scanning laser polarimetry and optical coherence tomography have all been used to evaluate optic disc topography ${ }^{34}$, there is not one clearly identified "gold standard". To facilitate gathering of data, we elected to use Optos for our study. Optos is available in a large number of primary eyecare practices and its use allows this study to generalize to routine clinical vision care. Again, either screening devices or gold standard testing could be used to create a normative data base of glaucoma specific physical ocular structures; it is only required that decisions as to which structures are abnormal be made by applying equipment consistently between groups. The Optos has software $\left(\mathrm{V}^{2}\right.$ Vantage 2.3.0.70) that calculates $\mathrm{C} / \mathrm{D}$ ratio and optic disc area in pixels. The basis for the topographic algorithm that permits $\mathrm{C} / \mathrm{D}$ ratio calculation has not been published.

\section{Conversion of Optos Measures (pixels) to $\mathrm{mm}^{2}$}

We developed a conversion to convert Optos measures in pixels to disc area in $\mathrm{mm}^{2}$. This conversion, which was determined by performing Optos and OCT on 82 eyes, is pixels multiplied by 0.0003 (see Figure 4). Applying this factor to our over-all data for optic disc area and $\mathrm{N}$-RRA gives

Average Optic Disc Area

$(7863.57 \times 0.0003)=2.36 \mathrm{~mm}^{2}$

Optic Disc St Dev

$(1630.42 \times 0.0003)=0.49 \mathrm{~mm}^{2}$

Average N-RRA

$(4785.88 \times 0.0003)=1.44 \mathrm{~mm}^{2}$

N-RRA St Dev

$(1161.14 \times 0.0003)=0.35 \mathrm{~mm}^{2}$.

When the standard deviation is taken into account the average range for the optic disc area would be between $1.87 \mathrm{~mm}^{2}$ ([7863.571630.42] $\times 0.0003)$ and $2.85 \mathrm{~mm}^{2}$ $([7863.57+1630.42] \quad \times 0.0003) . \quad \mathrm{A}$ thin N-RRA could be defined as one standard deviation below the mean; this would be 3624.74 pixels (4785.88 -1161.14) and would give a minimum expected N-RRA of $1.09 \mathrm{~mm}^{2}(3624.74 \times 0.0003)$.

Published norms for the HRT $\mathrm{II}^{34}$, which determines optic disc area and other neuro-retinal rim parameters, are a normal range of optic disc area between 1.69 and $2.82 \mathrm{~mm}^{2}$ and a minimum N-RRA of $1.20 \mathrm{~mm}^{2}$. These values correspond well to those we found (disc area $=1.87$ to $2.85 \mathrm{~mm}^{2}$, minimum
$\mathrm{N}-\mathrm{RRA}=1.09 \mathrm{~mm}^{2}$ ). Additionally, we found that our examiners use Optos to measure disc area with a $95 \% \mathrm{CI}$ of 415 pixels $\left(0.12 \mathrm{~mm}^{2}\right), \mathrm{C} / \mathrm{D}$ ratio with a $95 \%$ CI of 0.034 , and with repeatability of 171 pixels $\left(0.05 \mathrm{~mm}^{2}\right)$. Although the difference in repeatability is statistically significant, neither it nor the others are likely to be clinically significant. Taken together, these results suggest that the Optos (and, although not addressed by our data, perhaps other digitizing retinal cameras as well) can be used to accurately estimate $\mathrm{C} / \mathrm{D}$ ratio, disc area, and neuro-retinal rim area.

\section{Site Differences}

For Caucasian patients, our Canadian patients had smaller optic disc areas (7087.99+/-1871.1 vs $7392.88+/-1714.24)$ and thinner over-all N-RRA (4413.98+/1263.43 vs $4841.50+/-1379.51)$ than Texas patients. These differences were significant at the 0.01 level. It is likely that the difference stems from subtle differences in the drawing of the optic nerve parameters by the investigators. The dif ference would be about $0.09 \mathrm{~mm}^{2}$ $([7392.88$ - 7087.28] $\times$ 0.0003), similar to our reliability findings, and is unlikely to have any clinical significance.

\section{Racial differences in corneal thickness, C/D and optic disc area.}

Racial differences in corneal thickness were found in the OHTS. ${ }^{28}$ Since the OHTS subjects only included patients with ocular hypertension, it is reasonable to question whether these racial CCT differences would also be found in a clinical population with normal IOP 
or whether the OHTS differences were somehow related to ocular hypertension. Our results demonstrate a difference in CCT for patients over a broad range of ages and over all self-designated races (see Table 2). In addition to racial differences in CCT in our young patients, there were racial differences in $\mathrm{C} / \mathrm{D}$ ratio and optic nerve structure, as well as differences in their interrelations. Similar racial differences in $\mathrm{C} / \mathrm{D}$ ratio and optic nerve structure have been reported in glaucoma patients. ${ }^{25,27}$

\section{Clinical Application: Glaucoma Related Abnormal Structure Screening}

We are suggesting that decisions regarding which primary eye care patient to screen for glaucoma may be refined through increased knowledge of and attention to the normal range and interrelation among the CCT, $\mathrm{C} / \mathrm{D}$ ratio, inter eye $\mathrm{C} / \mathrm{D}$ ratio asymmetry, optic disc area, and N-RRA. Determining the relation between structures lends itself to a proposed Glaucoma Related Abnormal Structure Screening (GRASS). From Figure 2, 22.96\% of young normal patients and $65.52 \%$ of glaucoma patients have a Z-Score of 2.3 or greater.

A clinician could calculate the Zscore of each patient to accurately determine the deviation of ocular structures from the mean. However, rapid determination of $\mathrm{Z}$-scores is not a clinically easy task. One method of rapidly estimating the $Z$-score is to define abnormal structure as 1SD from the mean and assign each abnormal structure (CCT, C/D ratio, inter eye $\mathrm{C} / \mathrm{D}$ ratio asymmetry, optic disc area, and N-RRA) one point. This results in a 5 point score when all structures are abnormal (similar to that used for evaluation of many other ocular structures and functions).

From Table 4, patients with two or more abnormal structures (GRASS score of 2 or more) make up $18.72 \%$ of the young normal population and $74.55 \%$ of our glaucoma population (numbers that are similar to the Z-Score results in
Figure 2). Further, the percentages of patients with multiple structural abnormalities (who receive a GRASS score of 3 to 5) correspond well to numbers found in prospective glaucoma incidence studies. ${ }^{16,35-37}$ Indeed, the proportion of patients with abnormal ocular structure interrelation was as expected - higher for $\mathrm{Black}^{30}$, intermediate for Hispanic ${ }^{38}$, and lowest for Caucasian patients. ${ }^{30}$ Taken together, these results suggest that simply scoring one point for each abnormal structure (CCT, C/D ratio, inter eye $\mathrm{C} / \mathrm{D}$ ratio asymmetry, optic disc area, and N-RRA) will provide a useful clinical approximation of the abnormal structure ranking.

GRASS is an equipment-neutral procedure / approach. The mean and standard deviation of a structure is determined using a given piece of equipment (e.g, for C/D either Optos or the gold standard stereo photo could be used). The structure abnormality is then converted to a $Z$-score and this score is used in the GRASS calculation. In this manner, any given clinic can de-

TABLE 4

\section{GLAUCOMA-RELATED ABNORMAL STRUCTURE SCREENING (PERCENT PER CATEGORY)}

\begin{tabular}{|l|c|c|c|c|c|c|}
\hline Grass Score & $\mathbf{0}$ & $\mathbf{1}$ & $\mathbf{2}$ & $\mathbf{3}$ & $\mathbf{4}$ & $\mathbf{5}$ \\
\hline Black & 38.06 & 38.85 & 14.44 & 6.82 & 1.57 & 0.26 \\
\hline Caucasian & 53.08 & 35.78 & 10.26 & 0.59 & 0.29 & 0.00 \\
\hline Hispanic & 56.29 & 27.67 & 11.64 & 3.77 & 0.63 & 0.00 \\
\hline Asian & 43.24 & 33.78 & 14.86 & 8.11 & 0.00 & 0.00 \\
\hline Other (Indian/Pakistani) & 46.20 & 27.17 & 21.74 & 4.89 & 0.00 & 0.00 \\
\hline All & 49.82 & 32.79 & 12.97 & 4.46 & 0.36 & 0.09 \\
\hline
\end{tabular}

\begin{tabular}{|l|c|c|c|c|c|c|}
\hline Grass Score & 0 & 1 & 2 & 3 & 4 & 5 \\
\hline Glaucoma & 5.45 & 20.00 & 32.73 & 29.09 & 12.73 & 0.00 \\
\hline
\end{tabular}


determine a GRASS score as long as they have confidently determined the mean and standard deviation of a physical ocular structure for their equipment. If they use Optos, our numbers can be used.

\section{Glaucoma Related Abnormal Structure Screening (GRASS) Clinical Example}

Consider the optic discs Figure 5a and $5 \mathrm{~b}$. In Figure $5 \mathrm{a}$ is an optic disc of a 26 year old Asian female with a $\mathrm{C} / \mathrm{D}$ of 0.60 and in Figure $5 \mathrm{~b}$ is the optic disc of a 15 year old Hispanic male with a $\mathrm{C} / \mathrm{D}$ of 0.50 . Based on $\mathrm{C} / \mathrm{D}$ ratio alone a clinician would suspect that the patient in Figure $5 \mathrm{a}$ has a more abnormal structure. However, applying GRASS provides further information.

The patient in Figure 5a has a corneal thickness of $600 \mu \mathrm{m}$, an optic disc area of $4.22 \mathrm{~mm}^{2}$ (14068 pixels), an inter-eye $\mathrm{C} / \mathrm{D}$ ratio asymmetry of 0.01 , and a neuro-retinal rim area of $1.69 \mathrm{~mm}^{2}$ (5627 pixels). Clearly, although she has a large C/D ratio and her optic disc area is very large, her inter-eye $\mathrm{C} / \mathrm{D}$ ratio asymmetry and neuro-retinal rim area are both within the normal range. This gives her a Glaucoma Related Abnormal Structure Scale (GRASS) score of 2 - abnormal structures of large C/D and large optic disc area. Addition ally, her measured IOP is 12 and, when corrected for corneal thick ness, is even lower at 10.16 [12 $(0.50 \times 3.69)]$.

The patient in Figure 5b has a corneal thickness of $495 \mathrm{~mm}$, an optic disc area of $1.95 \mathrm{~mm}^{2}$ (6512 pixels), an inter-eye $\mathrm{C} / \mathrm{D}$ ratio asymmetry of 0.21 , and a neuro-retinal rim area of $0.98 \mathrm{~mm}^{2}$ (3256 pixels). For this
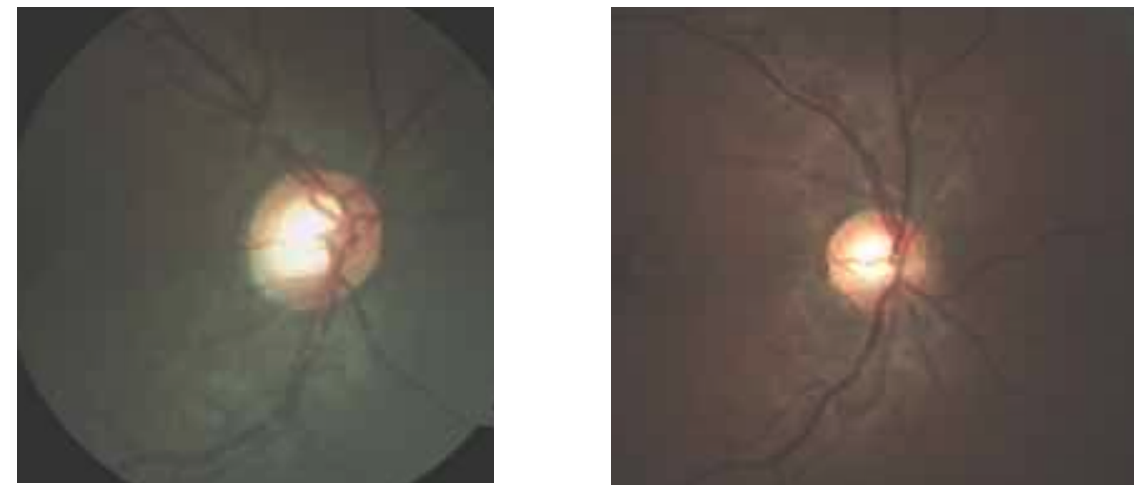

Figure 5a and 5b: Figure 5 a shows an optic nerve of a 26 year old Asian female with a $C / D$ of 0.60 and in Figure $5 b$ is the optic nerve of a 15 year old Hispanic male with a $C / D$ of 0.50. The patient in Figure 5 a has a GRASS score of 2 [optic nerve area of $2.82 \mathrm{~mm}^{2}$ (9399 pixels) and a neuro-retinal rim area of $1.21 \mathrm{~mm}^{2}$ (4041 pixels)]. The patient in Figure $5 b$ has a GRASS score of 4 [corneal thickness of $495 \mathrm{~mm}, C / D$ of 0.50 , inter-eye $C / D$ ratio asymmetry of 0.21 , neuro-retinal rim area of $1.06 \mathrm{~mm}^{2}$ (3549 pixels)]. Although these patients should both be followed closely, the GRASS score suggests that the glaucoma related ocular structure in Figure $5 b$ is of much more clinical concern than the one in Figure 5 a.

patient, although his optic disc area is small, he has a large $C / D$ ratio, an abnormal inter-eye $\mathrm{C} / \mathrm{D}$ ratio asymmetry, and his neuro-retinal rim area is well below normal. He has a high GRASS score of 4 since he has borderline $\mathrm{C} / \mathrm{D}$, thin cornea, inter-eye $\mathrm{C} / \mathrm{D}$ asymmetry, and thin neuroretinal rim. His IOP is 20 and, when corrected for corneal thickness, is above normal at $22.03[20+(0.55$ $\times 3.69)]$.

Although these patients could both be considered to have abnormal structure, the GRASS score suggests that the ocular structure of the patient in Figure $5 b$ is much more abnormal than the one in Figure $5 \mathrm{a}$. Based on analysis of these optic discs, the GRASS score has face validity - that is, it seems to make sense. It remains to be determined over time whether GRASS develops incremental validity in re- fining decisions on which primary eye care patient to screen for glaucoma (i.e., whether patients with greater scores actually show glaucomatous findings during glaucoma evaluation and subsequently go on to develop glaucoma in higher proportion to patients identified by other techniques).

\section{Sensitivity and Specificity}

Sensitivity is disease focused and describes the percentage of people with the disease that the test correctly identifies. A test with a sensitivity of $80 \%$ detects $80 \%$ of the abnormalities in the population studies (missing 20\%). GRASS has a Sensitivity of $74.55 \%$ - the number of our glaucoma patients with a GRASS score of 2 or more.

Specificity is wellness or normal focused and describes the percentage of normal people the test 
correctly identifies as normal. A test with $85 \%$ specificity correctly identifies $85 \%$ of healthy people as healthy $(15 \%$ are false positives - thought to have the disease when they do not). GRASS has a Specificity of $81.28 \%$ - the number of normal patients with a GRASS score of 0 or 1.

The GRASS $74.55 \%$ Sensitivity and $81.28 \%$ Specificity rate is very high for a clinical screening test. For example, no single value of IOP is considered to provide an acceptable balance of sensitivity and specificity for screening ${ }^{39}$. For example, in the Baltimore Eye Survey ${ }^{11}$, IOP $\geq 18 \mathrm{~mm} \mathrm{Hg}$ had sensitivity and specificity of $65 \%$; raising the cutoff to IOP $\geq 21 \mathrm{~mm} \mathrm{Hg}$ improved specificity to $92 \%$ but lowered sensitivity to $44 \%$. These results are due in part to fluctuations in IOP over time - only about $50 \%$ of patients with untreated glaucoma actually have IOP greater than 21 $\mathrm{mm} \mathrm{Hg}$ on random measurement. ${ }^{40}$ Although not tested by our data, presumably combining GRASS ocular structure screening with IOP could significantly raise the Predictive Value and provide a useful balance of sensitivity and specificity to determine which primary eye care patients to screen for glaucoma.

\section{Conclusion}

Data from this study provide new insight into the normal range and interrelation between CCT, C/D ratio, inter eye $C / D$ ratio asymmetry, optic disc area, and N-RRA and positive answers to our General Research Questions:

1) Can decisions to determine which patients to screen for glaucoma be refined by determining the normal ranges of specific physical ocular structures?

2) And, can this normative data of specific physical ocular structures be applied to age range of patients that participated to find those with anatomy similar to glaucoma patients?

GRASS is an equipment-neutral tool for use by the general clinician to screen for relative ocular structure abnormality using the results of routine clinic tests. The GRASS score will help determine which primary eye care patient should be screened for glaucoma. In this view, the GRASS score would be considered along with other glaucomatogenic factors including age, IOP value, diurnal pressure fluctuation, optic nerve perfusion, visual field testing, etc. to determine the appropriate over-all level of concern.

GRASS is not intended to predict glaucoma development but rather to identify patients with multiple structural abnormalities, regardless of age or IOP level. Providing more information than a simple $\mathrm{C} / \mathrm{D}$ ratio, evaluating and relating the ocular structures central corneal thickness, C/D ratio, inter-eye $\mathrm{C} / \mathrm{D}$ ratio asymmetry, optic disc area, and N-RRA, in patients below age 40, will help refine decisions on which primary eye care patient to screen for glaucoma. This, in turn, will help identify which young patients should be more closely followed for possible future development of glaucoma.

\section{Acknowledgements}

Presented in part as a poster at the AAO meeting in December 2005. Thanks to Jumah Absy, Susan Che, and Bonnie Cameron who participated in data gathering and analysis for the poster and to Harold Bedell, Susan Che, and Heather Johns-Anderson for comments on versions of this manuscript.

\section{Footnotes}

a. Patients being treated for glaucoma were those who, after thorough clinical evaluation, had been found to have continued and/or increasing nerve fiber layer loss (GDx or OCT) along with continued and or increasing visual field defects consistent with glaucoma (nasal step, bjerum scotoma, etc). These patients may or may not have had initial high IOP.

b. Except for corneal thickness, there were no statistically significant differences between male $(555.01+40.55)$ and female $(546.92+38.26)$ patients. Further, none of the between site measures were significantly different (except for two OPTOS measures). As a result, neither separate data for male and female patients nor between site measures are reported in Table 2.

\section{References}

1. Sommer A, Tielsch J, Katz J, et at. Racial differences in the cause-specific prevalence of blindness in East Baltimore. N Engl J Med 1991; 325:1412-7.

2. Spaeth GL, Heander J, Liu C, et al. The disc damage likelihood scale - reproducibility of a new method of estimating amount of optic nerve damage caused by glaucoma. Trans Am Ophthalmol Soc 2002;100:181-5.

3. Fingeret M. When is a case truly glaucoma? Optometry Times. 2009:Mar:36-7.

4. Von Graefe A. Vorlaufige notix uber des wesen des glaucoms. Graefes Arch Ophthalmol. 1854;1:371.

5. Duke-Elder S, Jay B. Introduction to glaucoma and hypotony. IN Duke-Elder S (ed). System of Ophthalmol. St Louis. Mosby. 1969, Vol XI, p337.

6. Kronfeld PC. The history of glaucoma. IN Duane's Clinical Ophthalmol. Vol 3. Philadelphia. Lippinncott. 1991, Chpt 41, p1.

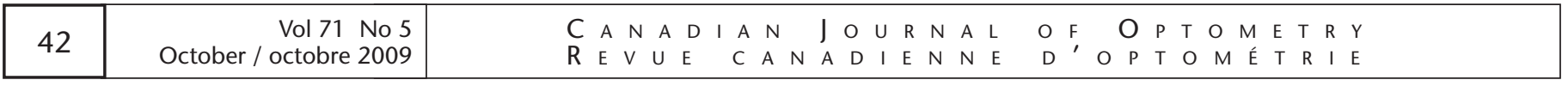


7. Phelps CD. Glaucoma: general concepts. IN Duane's Clinical Ophthalmol. Vol 3. Philadelphia. Lippinncott. 1991,Chpt 42, p1.

8. The Merck Manual of Diagnosis and Therapy. Whitehouse Station, NJ Merck Research Laboratories, 1999: 733.

9. Pointer JS. The diurnal variation of intraocular pressure in non-glaucomatous subjects: relevance in a clinical context. Ophthalmic Physiol Opt. 1997;17:456-65.

10. Shields MB. Textbook of Glaucoma. 3rd ed. Lippincott Williams \& Wilkins;1992.

11. Tielsch JM, Katz J, Singh K, Quigley HA, Gottsch JD, Javitt J,et al. A populationbased evaluation of glaucoma screening: the Baltimore Eye Survey. Am J Epidemiol 1991;134:1102-10

12. Mitchell P, Smith W, Chey T, Healey PR. Open-angle glaucoma and diabetes. The Blue Mountains Eye Study, Australia. Ophthalmology 1997;104:712-8.

13. Goldberg I: Relationship between Intraocular Pressure and Preservation of Visual Field in Glaucoma. Surv Ophthalmol 48 (Supp 1): S3—7, 2003.

14. Harwerth RS, Carter-Dawson L, Shen F, Smith EL, Crawford MLJ. Ganglion Cell Losses Underlying Visual Field Defects from Experimental Glaucoma. Investigative Ophthalmology and Visual Science. 1999;40:2242-50.

15. Varma R, Quigley HA, Pease ME. Changes in optic disk characteristics and number of nerve fibers in experimental glaucoma. Am J Ophthalmol. 1992;114:554-9.

16. Read RM, Spaeth GL. The practical clinical appraisal of the optic disc in glaucoma: the natural history of cup progression and some specific disc-field correlations. Trans Am Acad Ophthalmol Otolaryngol 1978;78:255.

17. Armaly MF. The optic cup in the normal eye: cup width, depth vessel displacement, ocular tension and outflow facility. Am J Ophthalmol 1969 Sept;68(23):401-7.

18. Varma R, Tielsch JM, Quigley HA, et al. Race-, age-, gender-, and refractive errorrelated differences in the normal optic disc. Arch Ophthalmol 1994;112:1068-76.

19. Chi T, Ritch R, Stickler D, et al. Racial differences in optic nerve head parameters. Arch Ophthalmol. 1989;107:836-9.

20. Quigley HA, Hohman RM, Addicks EM, et al. Morphologic changes in the lamina cribrosa correlated with neural loss in open angle glaucoma. Am J Ophthalmol. 1983;95:673-91.

21. Stodtmeister R. Applanation tonometry and correction according to corneal thickness. Acta Ophthalmol Scand. 1998;76:319-24.
22. Elsner AE, Burns SA, Weiter JJ, Delori FC. Infrared imaging of subretinal structures in the human ocular fundus. Vision Res 1996;36:191-205.

23. Britton RJ, Drance SM, Schulzer M, Douglas GR, Mawson DK. The area of the neuroretinal rim of the optic nerve in normal eyes. Am J Ophthalmol1987;103:497-504.

24. Bengtsson B. The variation and covariation of cup and disc diameters. Acta Ophthalmologica (Kbh) 1976;54: 804-18.

25. Lester M, Mikelberg FS, Courtright P, Drance SM. Correlation between the visual field indices and the Heidelberg retinal tomograph parameters. J Glaucoma 1997;6:78-82.

26. Jonas JB, Fernandez MC, Sturmer J. Pattern of glaucomatous neuroretinal rim loss. Ophthalmology 1993 Jan;100(1):63-8.

27. Quigley HA, Dunkelberger BS, Green WR. Retinal ganglion cell atrophy correlated with automated perimetry in human eyes with glaucoma. Am J Ophthalmol 1989;107(5):453-64

28. Gordon MO, Beiser JA, Brandt JD, et al. The Ocular Hypertension Treatment Study: baseline factors that predict the onset of primary open-angle glaucoma. Arch Ophthalmol 2002;120:714-720.

29. Quigley HA, Coleman AL, Dorman-Pease ME. Larger optic nerve heads have more nerve fibers in normal monkey eyes. Arch Ophthalmol 1991;109:1441-3.

30. Mason RP, Kosoko O, Wilson MR, et al. National survey of the prevalence and risk factors of glaucoma in St. Lucia, West Indies. Part I, Prevalence findings. Ophthalmol 1989;96:1363-8.
31. Moore DS, McCabe GP. Introduction to Practical Statistics, 4th ed. WH Freeman \& Co., NY, 2003: 469-474; 557-558.

32. Rosner B. Fundamentals of biostatistics. Boston: PWS-Kent Publishing Co., 1989:269.

33. Johnson CEJ. Consistency of reporting of ethnic origin in the current population survey. Bureau of Census, Washington D.C., U.S., Dept. of Commerce Technical Paper, no. 31, 1974.

34. Swindale NV, Stjepanovic G, Chin A, Mikelberg FS: Automated analysis of normal and glaucomatous optic nerve head topography images. Invest Ophthalmol Vis Sci 2000;41:1730-42.

35. Armaly MF, Krueger DE, Maunder L, et al. Biostatistical analysis of the collaborative glaucoma study, I: summary report of the risk factors for glaucoma visual fields. Arch Opthalmol 1980;98:2163-71.

36. Armaly MF. Ocular pressure and visual fields; a ten year follow-up study. Arch Ophthalmol 1969;81:25-40.

37. Bengtsson B. Manifest glaucoma in the aged, I: occurrence nine years after a population survey. Acta Ophthalmol (Copenh). 1981;59:321-31.

38. Quigley HA, West SK, Rodriguez J, Munoz B, Klein R, Snyder R. The prevalence of glaucoma in a population-based study of hispanic subjects: Proyecto VER. Arch Ophthalmol 2001;19:1819-26.

39. Tielsch JM. Screening for primary open-angle glaucoma: alternative strategies and future directions. J Glaucoma 1992;1:214-8.

40. Quigley HA. Open-angle glaucoma. N Eng J Med 1993;328:1097-06.

\section{PAR-MED PROPERTY SERVICES INC.}

PAR-Med is the recognized leader in property management of medical office buildings in Ontario. Opportunities exist within our portfolio for optometry services and dispensing.

TELEPHONE 416-364-5959 x403 1-800-663-5340 EMAIL: info@par-med.com www.par-med.com 